\title{
Cardiac support device, restrictive mitral valve annuloplasty, and optimized medical treatment: A multimodality approach to nonischemic cardiomyopathy
}

\author{
Jerry Braun, MD, ${ }^{\text {a }}$ Agnieszka Ciarka, MD, PhD, ${ }^{\mathrm{b}}$ Michel I. M. Versteegh, MD, ${ }^{\text {a }}$ Victoria Delgado, MD, ${ }^{\mathrm{b}}$ \\ Eric Boersma, MD, PhD, ${ }^{c}$ Harriette F. Verwey, MD, PhD, ${ }^{b}$ Martin J. Schalij, MD, PhD, ${ }^{b}$ \\ Jeroen J. Bax, MD, PhD, ${ }^{\mathrm{b}}$ Robert A. E. Dion, MD, PhD, ${ }^{\mathrm{d}}$ Nico R. van de Veire, MD, PhD, ${ }^{\mathrm{b}}$ and \\ Robert J. M. Klautz, MD, $\mathrm{PhD}^{\mathrm{a}}$
}

\begin{abstract}
Objective: Nonischemic dilated cardiomyopathy with functional mitral regurgitation carries a poor prognosis. Mitral valve surgery with implantation of a cardiac support device can treat mitral regurgitation and promote left ventricular reverse remodeling. This observational study evaluates clinical and echocardiographic outcomes of an individualized medico-surgical approach, focusing on mitral regurgitation recurrence and left ventricular reverse remodeling.
\end{abstract}

\begin{abstract}
Methods: Sixty-nine consecutive patients with heart failure (New York Heart Association class III/IV) with functional mitral regurgitation (grade $3+4+$ ) and left ventricular remodeling (end-diastolic volume $227 \pm 73$ $\mathrm{mL}$, ejection fraction $26 \% \pm 8 \%$ ) underwent restrictive mitral annuloplasty (median ring size 26), with $(n=41)$ or without $(n=28)$ a cardiac support device and optimal postoperative medical treatment. Patients were clinically and echocardiographically evaluated at up to 3.1 years' median follow-up.
\end{abstract}

Results: Early mortality was 5.8\%. Actuarial survival at 1, 2, and 5 years was $86 \% \pm 4 \%, 79 \% \pm 5 \%$, and $63 \% \pm 7 \%$. New York Heart Association class improved from $3.1 \pm 0.4$ to $2.0 \pm 0.5(P<.01)$. Cardiac support device implantation in addition to mitral valve surgery, applied in patients with more advanced left ventricular remodeling, resulted in similar clinical outcome, greater left ventricular end-diastolic volume decrease (33\% vs $18 \% ; P=.007$ ), and in a trend toward less recurrent mitral regurgitation of grade $2+$ or more (actuarial freedom at 3 years $89 \% \pm 8 \%$ vs $63 \% \pm 11 \% ; P=.067)$.

Conclusions: An individualized medico-surgical approach to nonischemic cardiomyopathy combining restrictive mitral annuloplasty, cardiac support device implantation, and optimal medical management leads to favorable survival and improved functional status, low incidence of significant recurrent mitral regurgitation, and sustained left ventricular reverse remodeling. (J Thorac Cardiovasc Surg 2011;142:e93-100)

Congestive heart failure resulting from nonischemic dilated cardiomyopathy with secondary functional mitral regurgitation (MR) carries a poor prognosis. ${ }^{1-4}$ Medical treatment results in a 1-year survival of $52 \%$ to $87 \%$ and a 5 -year survival of $22 \%$ to $54 \%,{ }^{1,2,4,5}$ with highest survivals presented in more recent years, probably reflecting improvements in medical therapy. Nonsurgical interventions involve cardiac resynchronization therapy (CRT) ${ }^{6}$ and cardiac rehabilitation. ${ }^{7}$ Implantation of an internal cardioverter

\footnotetext{
From the Departments of Cardiothoracic Surgery ${ }^{\mathrm{a}}$ and Cardiology, ${ }^{\mathrm{b}}$ Leids Universitair Medisch Centrum, Leiden, The Netherlands; the Department of Cardiology, ${ }^{c}$ Erasmus Medisch Centrum, Rotterdam, The Netherlands; and the Department of Cardiovascular Surgery, ${ }^{\mathrm{d}}$ Ziekenhuis Oost-Limburg, Genk, Belgium.

Disclosures: Authors have nothing to disclose with regard to commercial support.

Received for publication July 8, 2010; revisions received Nov 16, 2010; accepted for publication Dec 9, 2010; available ahead of print March 14, 2011.

Address for reprints: Jerry Braun, MD, Leids Universitair Medisch Centrum, Afdeling Thoraxchirurgie K6-S, Albinusdreef 2, 2333 ZA Leiden, The Netherlands (E-mail: j.braun@lumc.nl).

$0022-5223 / \$ 36.00$

Copyright (C) 2011 by The American Association for Thoracic Surgery

doi:10.1016/j.jtcvs.2010.12.027
}

defibrillator (ICD), often combined with CRT, improves survival by preventing death from life-threatening arrhythmias. ${ }^{8}$ Surgery is considered a third-line treatment for selected patients and includes cardiac transplantation and assist device implantation or nontransplantion surgery. In the latter category, the use of an undersized mitral annuloplasty ring to cure MR and to restore the shape of the spherical left ventricle (LV) to its normal ellipsoid form has been advocated by Bach and Bolling ${ }^{9,10}$ and has been adopted by others. ${ }^{11}$ The true benefit of this approach over nonsurgical treatment with regard to survival has been debated. ${ }^{12}$ More recently, external cardiac restraint or cardiac support devices (CSDs), for example, the CorCap device (Acorn CV, St Paul, Minn), have become available as additional surgical alternatives to treat nonischemic dilated cardiomyopathy. In a randomized trial, survival of patients with MR and nonischemic dilated cardiomyopathy who underwent mitral valve surgery with concomitant CSD implantation was similar to that of patients with mitral valve surgery alone after 2 years $(85 \%)$. Implantation of a CSD, however, resulted in a more extensive decrease of LV volumes. ${ }^{13}$ 


$$
\begin{aligned}
& \text { Abbreviations and Acronyms } \\
& \begin{aligned}
\mathrm{CRT} & =\text { cardiac resynchronization therapy } \\
\mathrm{CSD} & =\text { cardiac support device } \\
\mathrm{ICD} & =\text { internal cardioverter defibrillator } \\
\mathrm{IQR} & =\text { interquartile range } \\
\mathrm{LV} & =\text { left ventricle (ventricular) } \\
\mathrm{MR} & =\text { mitral regurgitation } \\
\mathrm{NYHA} & =\text { New York Heart Association }
\end{aligned}
\end{aligned}
$$

In this study, the clinical and echocardiographic outcome is assessed of all consecutive patients with heart failure who had nonischemic dilated cardiomyopathy and underwent restrictive mitral annuloplasty, with $(\mathrm{n}=41)$ or without $(\mathrm{n}=28)$ CSD implantation, in our nontransplantation surgical heart failure treatment program. Clinical outcome includes death, functional status, and adverse events (reoperation, readmission for heart failure). Echocardiographic examination focuses on recurrence of MR and LV reverse remodeling.

\section{PATIENTS AND METHODS}

\section{Patient Population and Indications for Surgery}

Sixty-nine consecutive patients with nonischemic dilated cardiomyopathy and functional MR who underwent surgery for heart failure since the start of our medico-surgical treatment program in August 2000 until January 2008 were included in this analysis, except patients with concomitant aortic valve disease. Patients were accepted for surgery regardless of ejection fraction or mitral valve geometry (ie, tenting height, leaflet angulation). Patients were in New York Heart Association (NYHA) heart failure class III $(86 \%)$ or IV; mean NYHA class was $3.1 \pm 0.4$ with optimal medical management. Mean MR grade was $3.1 \pm 0.6$. Mean logistic EuroSCORE was $11.9 \pm 9.2$ (range, 2.3-48). Seventy-four percent of patients had at least 1 contraindication for cardiac transplantation. Patient characteristics are presented in Table 1.

MR was treated with a restrictive semirigid complete ring annuloplasty. A tricuspid ring annuloplasty was performed in patients with significant tricuspid regurgitation ( $\geq$ grade $2+$ ) or (starting in 2003) when the tricuspid annulus diameter exceeded $40 \mathrm{~mm}$ or exceeded $21 \mathrm{~mm} / \mathrm{m}^{2}$ indexed to body surface area on transthoracic echocardiography. The use of external cardiac restraint by a CSD started in late 2002 in patients with an LV end-diastolic diameter exceeding $65 \mathrm{~mm}$ or exceeding $30 \mathrm{~mm} / \mathrm{m}^{2}$ indexed to body surface area.

Our institution's medical ethics committee approved this analysis of clinical data and waived the need for individual consent.

\section{Preoperative Clinical and Echocardiographic Assessment}

Preoperative clinical status was determined according to the NYHA criteria directly before surgery. Echocardiographic evaluation consisted of standard transthoracic examination within 5 days before surgery, including semiquantitative grading of severity of MR and tricuspid regurgitation, ${ }^{14}$ measurement of tricuspid annulus diameter, LV end-diastolic and endsystolic diameter, and left atrial size. LV volumes and LV ejection fraction were calculated according to Simpson's biplane method of disks. ${ }^{15}$ Baseline echocardiographic data are summarized in Table 1.

\section{Operative Technique}

All surgical procedures were performed via midline sternotomy with normothermic cardiopulmonary bypass and intermittent antegrade warm blood cardioplegia. In patients receiving a CSD, a CorCap CSD was implanted first on the beating heart with suture fixation of the device to the dorsal base of the heart along the atrioventricular groove. At the end of the surgical procedure, the CSD was tailored to meet the preoperative LV dimensions measured on transesophageal echocardiography, as described earlier. ${ }^{16}$ The mitral valve was exposed through a vertical transseptal approach along the right border of the foramen ovale. Ring size (Carpentier-Edwards Physioring; Edwards Lifesciences, Irvine, Calif) was determined after careful measurement of the height of the anterior leaflet and then downsizing by 2 ring sizes (ie, size 26 when measuring 30). ${ }^{17}$ Tricuspid annuloplasty was performed with a Carpentier-Edwards Classic (until 2003) or MC3 ring. Surgical data are summarized in Table 2.

Mitral valve repair was considered successful only if there was no residual MR and a leaflet coaptation length of at least $8 \mathrm{~mm}$ at the A2-P2 level on intraoperative echocardiogram.

\section{Postoperative Clinical and Echocardiographic Follow-up}

Transthoracic echocardiography was repeated before discharge on the seventh postoperative day and included assessment of the same parameters as in the preoperative examination, with the addition of mean transmitral diastolic gradient and mitral valve area calculated on the basis of pressure half-time. After hospital discharge, all but 3 patients were followed up in our outpatient heart failure clinic and received standardized optimal medical management, with regular echocardiographic follow-up.

Diastolic and systolic reverse remodeling at follow-up were defined as at least $15 \%$ reduction of $L V$ end-diastolic or end-systolic volume, respectively, compared with baseline volume.

\section{Statistical Analysis}

Continuous data are expressed as mean \pm standard deviation unless otherwise stated, and they were compared using the Student $t$ test for paired and unpaired data when appropriate. Proportions for dichotomous data were compared by $\chi^{2}$ analysis with Yates' correction. Survival and freedom from time-related events were estimated using the Kaplan-Meier method and analyzed using the Cox proportional hazard regression. Repeated measurements were analyzed by 2 -way analysis of variance. SPSS statistical software (SPSS version 16.0.2; SPSS, Inc, Chicago, Ill) was used for calculations.

\section{RESULTS}

All patients underwent successful mitral valve repair. Seventy-one percent of patients received a mitral ring size 24 or 26 . A CSD was implanted in $59 \%$ of patients, and tricuspid ring annuloplasty was performed in $73 \%$ of patients. Intraoperative echocardiography showed a competent mitral valve in all patients, without evidence of mitral stenosis.

\section{Immediate Outcome}

There was no intraoperative mortality. Nine $(13 \%)$ patients were supported by perioperative intra-aortic balloon counterpulsation, and $6(9 \%)$ required temporary hemodialysis, with an equal distribution among CSD and no-CSD patients. Overall early mortality (in-hospital and 30-day mortality) was $5.8 \%$ for the entire group (no-CSD $3.6 \%$, $\mathrm{n}=1 ; \operatorname{CSD} 7.3 \%, \mathrm{n}=3 ; P=.641)$. Three patients died of circulatory failure and 1 of septicemia secondary to pulmonary infection. 
TABLE 1. Preoperative clinical, laboratory and echocardiographic data for all patients, and arranged by CSD status

\begin{tabular}{|c|c|c|c|c|}
\hline Variable & All patients & Without CSD & With CSD & $P$ value \\
\hline No. of patients & 69 & 28 & 41 & \\
\hline Age (y) & $60 \pm 12$ & $56 \pm 14$ & $62 \pm 10$ & .07 \\
\hline Female gender (n) & $37(54 \%)$ & $19(68 \%)$ & $18(44 \%)$ & .08 \\
\hline NYHA class III & $59(86 \%)$ & $26(93 \%)$ & $33(80 \%)$ & .18 \\
\hline NYHA class IV & $10(14 \%)$ & $2(7 \%)$ & $8(20 \%)$ & .18 \\
\hline Logistic EuroSCORE & $11.9 \pm 9.2$ & $10.8 \pm 7.2$ & $12.7 \pm 10.2$ & $>.2$ \\
\hline Diabetes & $16(23 \%)$ & $7(25 \%)$ & $9(22 \%)$ & $>.2$ \\
\hline Chronic obstructive pulmonary disease & $12(17 \%)$ & $5(18 \%)$ & $7(17 \%)$ & $>.2$ \\
\hline Atrial fibrillation & $18(26 \%)$ & $6(21 \%)$ & $12(29 \%)$ & $>.2$ \\
\hline ICD before surgery & $12(17 \%)$ & $3(11 \%)$ & $9(22 \%)$ & $>.2$ \\
\hline CRT before surgery & $8(12 \%)$ & $2(7 \%)$ & $6(15 \%)$ & $>.2$ \\
\hline $\begin{array}{l}\text { ACE inhibitor or AT2 receptor } \\
\text { antagonist therapy }\end{array}$ & $62(90 \%)$ & $24(86 \%)$ & $38(93 \%)$ & $>.2$ \\
\hline Beta-blocker therapy & $54(78 \%)$ & $22(79 \%)$ & $32(79 \%)$ & $>.2$ \\
\hline Diuretic therapy & $64(93 \%)$ & $25(91 \%)$ & $39(95 \%)$ & $>.2$ \\
\hline Spironolactone therapy & $35(51 \%)$ & $17(62 \%)$ & $18(44 \%)$ & $>.2$ \\
\hline Systolic blood pressure $(\mathrm{mm} \mathrm{Hg})$ & $115 \pm 17$ & $122 \pm 19$ & $113 \pm 15$ & .09 \\
\hline Pulmonary hypertension & $27(40 \%)$ & $10(36 \%)$ & $17(41 \%)$ & $>.2$ \\
\hline Creatinin $(\mu \mathrm{mol} / \mathrm{L})$ & $110 \pm 42$ & $120 \pm 50$ & $103 \pm 35$ & .17 \\
\hline Plasma sodium $(\mu \mathrm{mol} / \mathrm{L})$ & $140 \pm 4$ & $140 \pm 5$ & $140 \pm 4$ & $>.2$ \\
\hline \multicolumn{5}{|l|}{ Mitral regurgitation grade } \\
\hline Grade $2+$ & 8 & 3 & 5 & \\
\hline Grade $3+$ & 45 & 19 & 26 & \\
\hline Grade $4+$ & 16 & 6 & 10 & \\
\hline LV end-diastolic diameter $(\mathrm{mm})$ & $67 \pm 9$ & $65 \pm 11$ & $69 \pm 7$ & .07 \\
\hline LV end-systolic diameter $(\mathrm{mm})$ & $60 \pm 10$ & $57 \pm 12$ & $63 \pm 7$ & .03 \\
\hline LV end-diastolic volume (mL) & $227 \pm 73$ & $201 \pm 80$ & $245 \pm 63$ & .02 \\
\hline indexed to BSA $\left(\mathrm{mL} / \mathrm{m}^{2}\right)$ & $118 \pm 38$ & $108 \pm 39$ & $133 \pm 32$ & .009 \\
\hline LV end-systolic volume $(\mathrm{mL})$ & $171 \pm 65$ & $150 \pm 71$ & $186 \pm 57$ & .03 \\
\hline LV ejection fraction $(\%)$ & $26 \pm 8$ & $28 \pm 9$ & $25 \pm 8$ & .13 \\
\hline Left atrial diameter $(\mathrm{mm})$ & $46 \pm 8$ & $45 \pm 10$ & $47 \pm 6$ & $>.2$ \\
\hline Mean transtricuspid pressure gradient $(\mathrm{mm} \mathrm{Hg})$ & $31 \pm 10$ & $30 \pm 9$ & $31 \pm 11$ & $>.2$ \\
\hline
\end{tabular}

$C S D$, Cardiac support device; $N Y H A$, New York Heart Association; $I C D$, internal cardioverter defibrillator; $C R T$, cardiac resynchronization therapy; $A C E$, angiotensin-converting enzyme; $A T 2$, angiotensin II type $2 ; L V$, left ventricular; $B S A$, body surface area. $P$ values given for comparison between patients with and without CSD.

Twenty-two (34\%) patients were scheduled preoperatively to receive CRT-ICD therapy, which was realized within 1 week after surgery during the same admission period.

\section{Survival}

Clinical follow-up was complete for the remaining 65 patients. Median follow-up was 3.1 years (interquartile range [IQR], 1.4-4.1 years). For the no-CSD group it was 4.3 years (IQR, 1.9-5.8 years) and for the CSD group it was 2.4 years (IQR, 1.3-4.0 years).

There were 18 late deaths during follow-up (no-CSD, 12; CSD, 6), with $50 \%$ of deaths resulting from cardiac causes. Overall survival (Kaplan-Meier estimate) at 1 year, 2 years, and 5 years was $86 \% \pm 4 \%, 79 \% \pm 5 \%$, and $63 \% \pm 7 \%$,

TABLE 2. Surgical and early postoperative data for all patients, and arranged by CSD status

\begin{tabular}{|c|c|c|c|c|}
\hline Variable & All patients & Without CSD & With CSD & $P$ value \\
\hline CPB time (min) & $132 \pm 33$ & $126 \pm 25$ & $136 \pm 36$ & $>.2$ \\
\hline Aortic crossclamp time (min) & $73 \pm 22$ & $74 \pm 18$ & $72 \pm 24$ & $>.2$ \\
\hline Median mitral annuloplasty ring size (range) & $26(24-30)$ & $26(24-30)$ & $26(24-30)$ & $>.2$ \\
\hline Ring size 24 (n) & $28(41 \%)$ & $11(40 \%)$ & $17(42 \%)$ & $>.2$ \\
\hline Ring size 26 (n) & $21(30 \%)$ & $8(29 \%)$ & $13(32 \%)$ & $>.2$ \\
\hline Tricuspid valve annuloplasty (n) & $50(73 \%)$ & $16(57 \%)$ & $34(83 \%)$ & .04 \\
\hline Median postoperative ventilator assist (d; range) & $0.5(0.5-40)$ & $1(0.5-40)$ & $0.5(0.5-10)$ & $>.2$ \\
\hline Median postoperative ICU stay (d; range) & $2(1-49)$ & $3(1-49)$ & $2(1-24)$ & $>.2$ \\
\hline Median postoperative hospital stay (d; range) & $12(6-80)$ & $12(5-80)$ & $12(5-30)$ & $>.2$ \\
\hline
\end{tabular}

$C S D$, Cardiac support device; $C P B$, cardiopulmonary bypass; $I C U$, intensive care unit. $P$ values given for comparison between patients with and without CSD. 

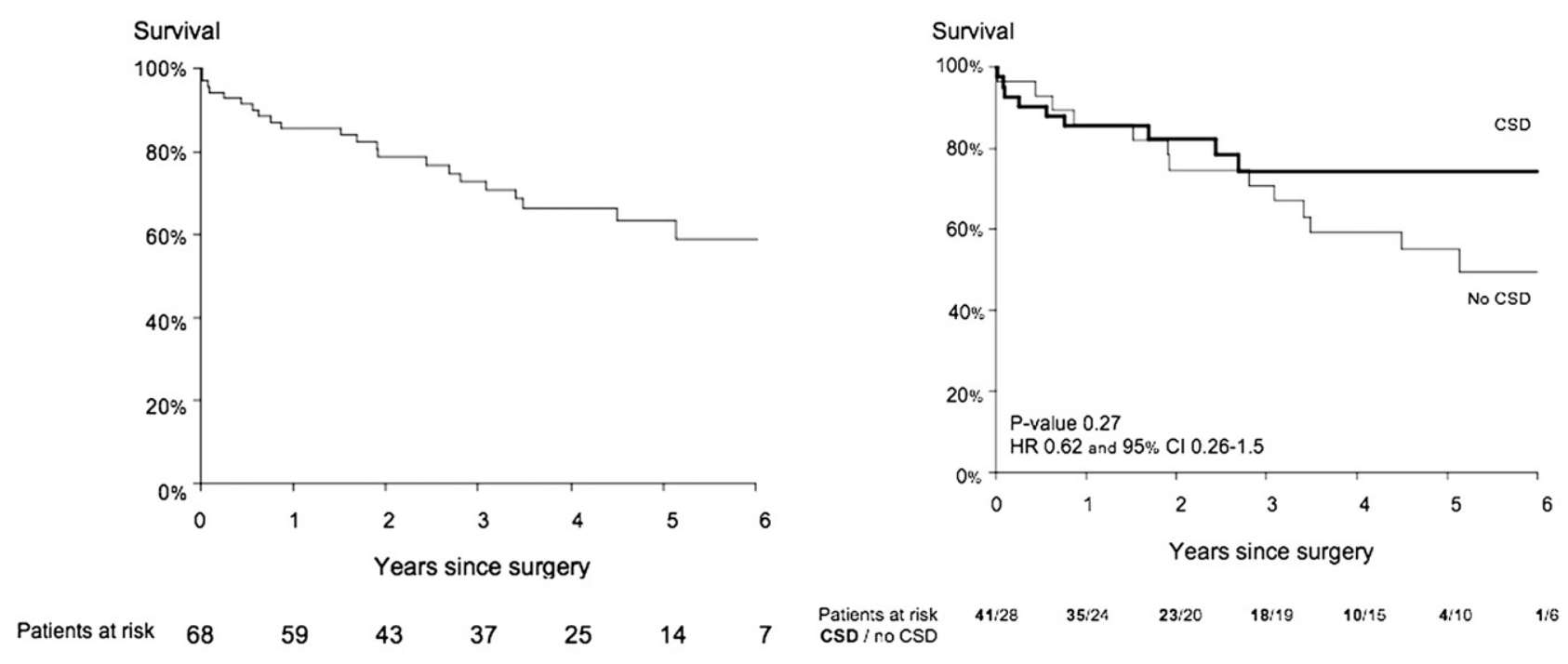

\section{A}

FIGURE 1. A, Survival estimated by Kaplan-Meier method for all patients. B, Survival estimated by Kaplan-Meier method for cohorts with and without a cardiac support device (CSD). Patients at risk per cohort are shown under the horizontal axis (CSD presented in boldface; no-CSD in regular type). HR, Hazard ratio; $C I$, confidence intervals.

respectively (Figure 1, $A$ ). For the no-CSD group, these percentages were $86 \% \pm 7 \%, 75 \% \pm 8 \%$, and $55 \% \pm 10 \%$, respectively, versus $85 \% \pm 6 \%, 82 \% \pm 6 \%$, and $74 \% \pm$ $8 \%$ for the CSD group, without significant difference (Figure 1, B).

\section{Adverse Events}

Thirteen $(20 \%)$ patients were readmitted for heart failure. The incidence of hospital readmissions for heart failure was 1 per 5.84 patient-years (38 readmissions in 222.3 patient-years). Eight (62\%) of these 13 patients died during follow-up (mean interval between first readmission and death, 8 months; range 1-17 months), and 1 is on the cardiac transplantation waiting list.

Eleven patients received CRT/ICD therapy during follow-up. Of 42 patients with ICD registration analysis, $24(57 \%)$ had at least 1 episode of ventricular tachycardia, of whom 14 had sustained ventricular tachycardia requiring antitachycardia pacing or shock $(\mathrm{n}=3)$. Two patients had successful shock therapy for ventricular fibrillation.

There were 3 cases of partial mitral ring dehiscence. One patient (CSD group) underwent successful refixation 2 months after the initial operation. Two other patients (without CSD) did not have reoperation; 1 had malignant disease, and the other declined redo surgery. Two patients had an ischemic cerebrovascular accident ( 1 fatal and the other with complete recovery), and another patient had a peripheral arterial embolism.

\section{Long-Term Clinical Outcome}

For long-term survivors, mean NYHA class improved from $3.1 \pm 0.4$ to $2.0 \pm 0.5(P<.01)$, with $5(11 \%)$ patients in NYHA class III, with similar results in the CSD and noCSD groups. Forty-three $(91 \%)$ surviving patients experienced improvement of symptoms (Figure 2).

\section{Echocardiographic Outcome}

Echocardiographic follow-up for hospital survivors was available for all but 3 patients ( $95 \%$ complete). Mean late echocardiographic follow-up time was $2.3 \pm 1.4$ years (IQR 1.0-3.5) and was similar for the CSD and no-CSD groups ( $2.2 \pm 1.4$ years and $2.6 \pm 1.4$ years, respectively). Echocardiographic data, summarized in Table 3, also include results in patients who died during follow-up.

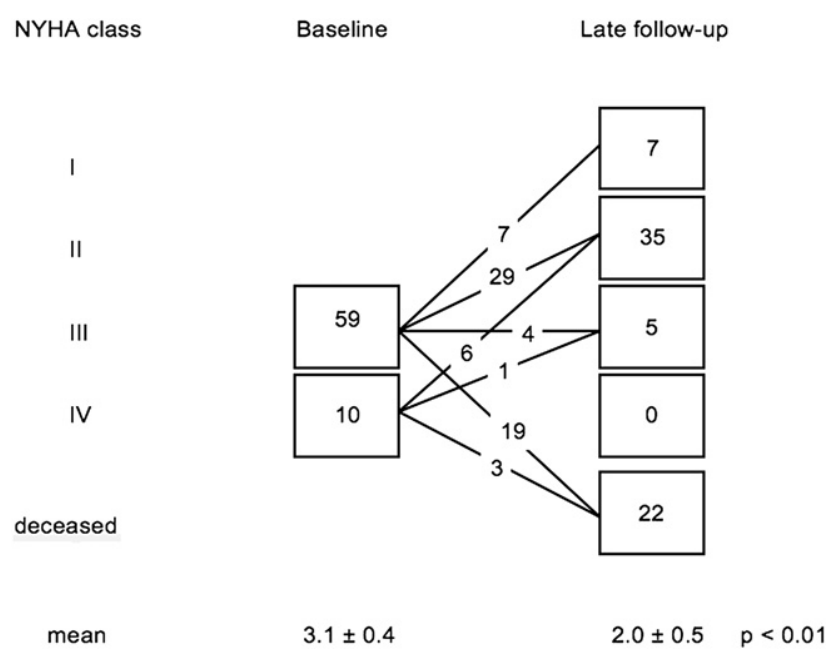

FIGURE 2. Clinical status according to New York Heart Association (NYHA) criteria at baseline and at late follow-up. 
TABLE 3. Echocardiographic parameters for all patients with available complete preoperative, early postoperative, and long-term follow-up data

\begin{tabular}{|c|c|c|c|}
\hline Variable & Preoperatively & Early postoperatively & Long-term follow-up \\
\hline \multicolumn{4}{|l|}{ MR grade } \\
\hline None & - & 53 & 30 \\
\hline Grade $1+$ & - & 15 & 22 \\
\hline Grade $2+$ & 8 & - & 7 \\
\hline Grade $3+$ & 45 & - & 2 \\
\hline Grade $4+$ & 16 & - & 1 \\
\hline LV end-diastolic diameter (mm) & $68 \pm 9$ & $63 \pm 9 *$ & $60 \pm 11^{*}$ \\
\hline LV end-systolic diameter ( $\mathrm{mm})$ & $61 \pm 10$ & $56 \pm 10^{*}$ & $54 \pm 12 *$ \\
\hline LV end-diastolic volume (mL) & $227 \pm 73$ & $205 \pm 72 *$ & $161 \pm 63^{*} \dagger$ \\
\hline LV end-systolic volume (mL) & $171 \pm 65$ & $153 \pm 66^{*}$ & $116 \pm 55^{*} \dagger$ \\
\hline LV ejection fraction $(\%)$ & $26 \pm 8$ & $25 \pm 8$ & $29 \pm 11$ \\
\hline Left atrial diameter (mm) & $46 \pm 8$ & $44 \pm 8^{*}$ & $44 \pm 8^{*}$ \\
\hline Mean transmitral diastolic gradient $(\mathrm{mm} \mathrm{Hg})$ & $1.8 \pm 0.9$ & $4.0 \pm 1.3^{*}$ & $3.6 \pm 1.8^{*}$ \\
\hline Mitral valve area $\left(\mathrm{cm}^{2}\right)$ & $3.8 \pm 1.2$ & $3.3 \pm 0.8$ & $3.0 \pm 1.0^{*}$ \\
\hline Mean transtricuspid pressure gradient $(\mathrm{mm} \mathrm{Hg})$ & $33 \pm 10$ & $24 \pm 8^{*}$ & $28 \pm 10^{*}$ \\
\hline
\end{tabular}

$M R$, Mitral regurgitation; $L V$, left ventricular. $* P<.001$ versus preoperative echocardiography. $\dagger P<.001$ versus early postoperative echocardiography.

Therefore, these data truly represent therapeutic effects, rather than being the consequence of attrition through death.

\section{MR and Stenosis}

MR decreased significantly at early postoperative and late follow-up. At late follow-up, $16 \%$ of patients had MR grade $2+$ or more. In the no-CSD group this percentage was $28 \%$ versus $8.3 \%$ in the CSD group. Actuarial freedom from recurrent MR of grade $2+$ or more at 3 years is $89 \% \pm$ $8 \%$ in the CSD group versus $63 \% \pm 11 \%$ in the no-CSD group $(P=.067)$. Cox regression analysis did not reveal any predictors for recurrence of MR (forcing CSD implantation, CRT/ICD therapy, and LV end-diastolic volume at baseline into the model). Sixty percent of patients who had recurrent MR died during follow-up. Mean transmitral gradient was elevated $(>5 \mathrm{~mm} \mathrm{Hg})$ in $3(5 \%)$ patients.

\section{Reverse Remodeling and Function}

LV volumes decreased over time (Figure 3). Initial reduction of volumes (from preoperatively to early postoperatively) was similar in both groups. At late follow-up, a higher decrease was observed in the CSD group: mean $\mathrm{LV}$ end-diastolic volume reduction was $-82 \mathrm{~mL}$ versus $-39 \mathrm{~mL}$, or $33 \%$ vs $18 \%(P=.007)$. LV end-systolic volume reduction was $-66 \mathrm{~mL}$ versus $-34 \mathrm{~mL}$, or $34 \%$ versus $20 \%(P=.042)$. Whereas baseline volumes in the CSD group were significantly higher, the values at late followup did not differ between the 2 groups. Two-way analysis of variance showed that the difference in magnitude of reverse remodeling comparing the CSD and no-CSD groups is statistically significant; linear regression indicated that both implantation of CSD $(P=.041)$ and end-diastolic volume at baseline $(P<.001)$ were determinants of final enddiastolic volume, with the effect of CSD implantation being independent of initial end-diastolic volume (interaction variable $P=.658$ ). Diastolic reverse remodeling at late followup was present in $76 \%$ of patients (CSD, $88 \%$; no-CSD, $61 \%$ ), and systolic reverse remodeling occurred in $73 \%$ (CSD, 81\%; no-CSD, 61\%). LV ejection fraction increased from $29 \% \pm 8 \%$ to $30 \% \pm 7 \%$ in the no-CSD group $(P=.426)$ and from $25 \% \pm 8 \%$ to $29 \% \pm 13 \%$ in the CSD group $(P=.123)$.

\section{Comparison Between Survivors and Nonsurvivors}

There were no differences between survivors and nonsurvivors with regard to preoperative demographics, medical treatment, laboratory values, or baseline echocardiographic characteristics. Although survivors had relatively more often CRT/ICD therapy ( $77 \%$ vs $44 \%$ ) and CSD implantation $(68 \%$ vs $33 \%)$, differences were not significant using Cox regression; for CRT/ICD therapy: hazard ratio, $0.50 ; 95 \% \mathrm{CI}, 0.16-1.55 ; P=.228$; for CSD: hazard ratio, $0.27 ; 95 \%$ CI, $0.26-1.45 ; P=.267$.

\section{COMMENT}

This study describes the long-term clinical and echocardiographic outcome of a nontransplantion medico-surgical treatment program in a consecutive series of patients with nonischemic dilated cardiomyopathy and functional MR, with moderately severe or severe congestive heart failure despite optimal medical treatment. The main findings of this study are as follows: (1) mitral valve repair with a restrictive mitral annuloplasty with or without external LV constraint using a CSD leads to improvement of functional status and a favorable long-term survival; (2) restrictive mitral annuloplasty, with or without external LV constraint, leads to a low incidence of significant recurrent MR and to reverse LV remodeling in a vast majority of patients, which is sustained at long-term follow-up; (3) additional CSD implantation in 

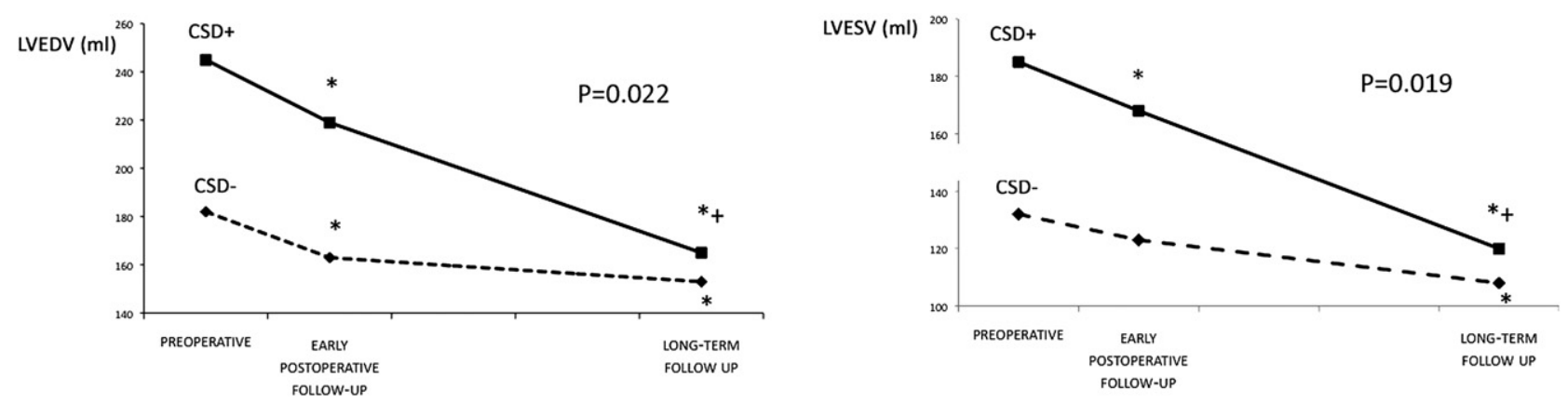

FIGURE 3. Left panel: Evolution of left ventricular end-diastolic volumes ( $L V E D V)$ preoperatively, at early postoperative follow-up, and at long-term follow-up in patients with a cardiac support device ( $C S D+$, solid line) and without a cardiac support device (CSD-, interrupted line). $P$ value given for 2-way analysis of variance for repeated measurements, comparing between subjects effects with CSD as a factor. Significant value indicates a difference in development of volumes over time between both groups. Comparisons within groups for volumes at different times were performed with Bonferroni posthoc comparisons and indicated as follows: $* P<.01$ versus preoperative, $\uparrow P<.01$ versus early postoperative echocardiogram. Right panel: Similarly, evolution of left ventricular end-systolic volumes (LVESV) throughout the follow-up.

patients with more advanced LV remodeling leads to more $\mathrm{LV}$ volume reduction, resulting in similar LV end-diastolic volumes at late follow-up comparing patients with and without CSD; and (4) CSD implantation shows a trend toward a lower incidence of recurrent MR.

The treatment strategies presented result from an ongoing conceptualization, implementation, and evaluation of individualized surgical and nonsurgical interventions in patients with heart failure. The surgical mainstay of this approach is the treatment of functional MR as described by Bach and Bolling, ${ }^{9,10}$ with a consistent and reproducible technique: implantation of a (semi-)rigid complete mitral annuloplasty ring using stringent downsizing by 2 ring sizes. In patients with ischemic cardiomyopathy and preoperative LV enddiastolic dimension of $65 \mathrm{~mm}$ or less, this strategy provides good clinical outcome, absence of significant recurrent MR, and sustained LV reverse remodeling, but in patients with more extensive LV remodeling results remain poor. ${ }^{17,18}$ This finding initiated the use of external cardiac constraint with a CorCap CSD in patients with heart failure who had an LV end-diastolic dimension greater than 65 $\mathrm{mm}$ or greater than $30 \mathrm{~mm} / \mathrm{m}^{2}$ indexed to body surface area, starting November 2002. Another strategy change involved the extended indication for a tricuspid ring annuloplasty in patients with annular dilatation (diameter on transthoracic echocardiography $>40 \mathrm{~mm}$ ) from September 2003 onward, initiated by the results of Dreyfus and associates. ${ }^{19}$ Patients with an LV ejection fraction less than $30 \%$ to $35 \%$ receive ICD therapy to lower the risk of sudden cardiac death since the results of the DEFINITE trial ${ }^{8}$ became available, whereas CRT is used as an adjuvant therapy to address mechanical and electrical dyssynchrony after the results of the CARE-HF trial. ${ }^{6}$

It is impossible to distinguish the separate effects of pharmacologic therapy, CRT/ICD therapy, cardiac rehabilitation, and all different surgical interventions on survival, MR, and LV reverse remodeling. However, a critical ap- praisal of what is known in the literature regarding the effects of these different treatment modalities is necessary to put the conclusions of the current study into perspective.

\section{Studies on Surgical Treatment of Nonischemic Cardiomyopathy}

Outcome data for surgical treatment of nonischemic cardiomyopathy are scarce, and most studies combine ischemic and nonischemic causes. Bolling ${ }^{10}$ presented the cases of 140 patients with end-stage heart failure, of whom two thirds had a nonischemic etiology. Patients had low ejection fraction $(16 \%)$ and increased LV end-diastolic volume $(281 \mathrm{~mL})$. All patients received an undersized mitral ring annuloplasty. The series from Gummert and colleagues ${ }^{11}$ includes 53 patients with nonischemic cardiomyopathy who received an undersized mitral ring annuloplasty (median ring size 28). Mean ejection fraction was $25 \%$, and $\mathrm{LV}$ end-diastolic dimension was $69 \mathrm{~mm}$. In the Acorn trial, ${ }^{13}$ 300 patients ( $90 \%$ nonischemic cardiomyopathy) were randomized either to mitral valve surgery with or without CSD or to medical therapy with or without CSD. Patients were in NYHA class II to IV with a $24 \% \mathrm{LV}$ ejection fraction (up to $45 \%$ ) and an LV end-diastolic volume of $270 \pm 100 \mathrm{~mL}$. For comparison, our study involves 69 patients with only nonischemic cardiomyopathy, NYHA class III/IV, ejection fraction $26 \% \pm 8 \%$, and LVend-diastolic volume $227 \pm 73 \mathrm{~mL}$.

\section{Effects on Survival and Functional Status}

Early mortality in the present study $(5.8 \%)$ is comparable with that in the series of Bolling ${ }^{10}(6 \%)$ and Gummert and associates $^{11}(6.1 \%)$, but higher than reported in the Acorn trial $(1.6 \%),{ }^{13}$ which however also includes patients with less severe heart failure (23\% of patients in NYHA class II and $41 \%$ of patients with MR grade $2+$ ). Our long-term actuarial survival in the no-CSD group equals that of Bol$\operatorname{ling}^{10}$ ( $52 \%$ at 5 years vs $55 \%$ in the current study); Gummert and associates ${ }^{11}$ report a crude mortality of $25 \%$ and 7 
cardiac transplantations at 2.3 years' follow-up. Crude mortality in the Acorn trial was $26 \%$ at 3 years, without differences between CSD and no-CSD groups ${ }^{20}$ as also noted in our study. Actuarial 5-year survival for the CSD group in the current study $(74 \% \pm 8 \%)$ cannot be compared with other studies.

The beneficial effect of mitral valve surgery for functional MR on survival has been debated by $\mathrm{Wu}$ and associates $^{12}$ in a study reflecting data from 1995 to 2002, when this type of surgery was emerging. Wu's group uses propensity analysis to compare event-free survival (freedom from death, LV assist device implantation, or cardiac transplantation) between patients who underwent undersized mitral annuloplasty and patients who were candidates for mitral valve repair based on echocardiography but did not undergo surgery. In the nonischemic group (276 patients), only 37 patients underwent mitral valve surgery. Event-free survival is similar for surgically and medically treated patients. However, the group not undergoing mitral valve surgery was favored by younger age, greater likelihood of spironolactone treatment, and more ICD therapy; LV ejection fraction was lower. In addition, no information on clinical status of these patients is provided, no echocardiographic examinations were performed, and a high likelihood of leadtime bias favoring the nonsurgical group is present. As such, statements on the true benefit of mitral valve surgery over medical therapy remain speculative.

Mortality in heart failure is directly related to LV remodeling. In the BEST trial (Beta-blocker Evaluation of Survival), LV end-diastolic volume indexed to body surface area exceeding $120 \mathrm{~mL} / \mathrm{m}^{2}$ was an independent predictor of death. ${ }^{21}$ Interestingly, in our group $51 \%$ of patients had an indexed LV end-diastolic volume greater than $120 \mathrm{~mL} / \mathrm{m}^{2}$ (CSD 60\%; no-CSD 35\%), but mortality was similar for these 2 groups, indirectly suggesting a relative survival benefit for patients with a more dilated LV in the current treatment program.

Survival in our series is certainly positively influenced by standardized optimal pharmacologic therapy and by CRT/ICD therapy, which are mainstays of nonsurgical heart failure treatment. CRT improves survival in patients with NYHA class III/IV heart failure who have LV dyssynchrony, ${ }^{6}$ but the high incidence of sudden death in CRT patients in the CArdiac REsynchronization-Heart Failure (CARE-HF) trial leaves room for additional ICD therapy. ${ }^{22}$ In our series, CRT/ICD therapy was always combined.

\section{Effects on MR and LV Reverse Remodeling}

All available echocardiographic data, including those of nonsurvivors, were analyzed, and therefore echocardiographic results reflect the true effects of the combined medico-surgical treatment program.

The sustained abolishment of functional MR by stringent downsizing by 2 ring sizes using a complete semirigid ring has been shown before. ${ }^{10,18}$ High MR recurrence rates in (ischemic) patients as reported in other series might be related to inconsistencies in patient selection and surgical techniques. ${ }^{23}$

In the current study, patients receiving a CSD had a trend toward a lower incidence of recurrent MR of grade 2 or more. This effect was also found in the Acorn trial. Most likely, the potentially beneficial effects of CSD implantation on $\mathrm{LV}$ volumes result from reduced tethering of the mitral valve subvalvular apparatus with reduction of MR, which in turn further decreases LV volumes.

CRT has shown a decrease in MR severity in nonischemic cardiomyopathy both acutely and after 1 year; effective regurgitant orifice area decreased by $40 \%$ to $50 \%{ }^{24,25}$ and average MR jet area by $45 \%{ }^{26}$ This is explained by shorter closing time of the mitral valve owing to improved LV contraction. However, the effect is highly variable between patients, and approximately $35 \%$ of patients do not show any response.

In the current study, long-term LV reverse remodeling was observed in $75 \%$ of patients. The magnitude of $L V$ volume decrease was significantly greater in the CSD group: although these patients had significantly higher LV volumes at baseline, these differences had disappeared at late follow-up.

Bolling ${ }^{10}$ showed a $27 \%$ decrease of LV end-diastolic volume at 2 years by mitral valve repair alone. In our series, LV end-diastolic volume decreased by $18 \%$ after mitral repair only and by $35 \%$ after CSD implantation.

In the Acorn trial at 2.3 years, $\mathrm{LV}$ end-diastolic volume after mitral valve surgery decreased by only $17 \%$ compared with $24 \%$ in the mitral valve surgery plus CSD group. These effects appeared 3 to 6 months after surgery and were maintained thereafter.

It is reasonable to expect that the initial drop of LV volumes results from the abrupt decrease in LV volume overload after restoration of mitral valve competence, and that it is independent of initial LV volume. Further decrease (true reverse remodeling), however, is probably the consequence of changes at a cellular level that are intuitively more likely to occur in less dilated ventricles. Therefore, we believe that the progressive LV volume decrease in the CSD group, leading to similar LV end-diastolic volumes at late follow-up, reflects a true beneficial effect of the CSD.

The effect of CRT on LV reverse remodeling was evaluated in the CARE-HF trial. ${ }^{27}$ It appeared between 3 and 9 months after initiation and was sustained at 29 months; at that time, LV end-diastolic volume had decreased by $19 \%$ and end-systolic volume by $26 \%$. Forty-nine percent of patients showed at least $15 \%$ volume reduction at 18 months' follow-up, as compared with $19 \%$ in the medically treated group.

In conclusion, an individualized combined medical and surgical approach to patients with congestive heart failure of nonischemic etiology and MR that includes standardized 
pharmacologic treatment, CRT/ICD therapy, consistent restrictive mitral annuloplasty surgery in all patients, and CSD implantation in patients with advanced LV remodeling leads to favorable survival, clinical improvement, low incidence of significant recurrent MR, and sustained LV reverse remodeling at longer follow-up. Additional CSD implantation in patients with more advanced LV remodeling leads to greater LV volume reduction and to a tendency toward less recurrent MR. Longer follow-up is necessary to establish whether this can further improve survival.

\section{STUDY LIMITATIONS}

This study has an observational nature without a control group. Patients were subjected to individualized treatments, which have changed over time with growing knowledge, and which were based on preoperative characteristics. By definition, selection bias was introduced. Among 12 patients who underwent surgery before the CSD became available, 9 actually would have qualified to receive a CSD on the basis of LV end-diastolic dimension. When these patients are left out of the analyses, the conclusions of this study remain unchanged with regard to survival, $L V$ reverse remodeling, and recurrence of MR.

In addition, the lack of a control group makes it hard to draw conclusions regarding observed differences in this study. We would emphasize, however, that patients in the CSD group, on the basis of their higher baseline LV volumes, would be expected to have a poorer survival and a lower chance of reverse remodeling with an associated higher chance of recurrent MR. In this study, clinical and echocardiographic outcomes are at least similar, indirectly suggesting a beneficial effect of applying the CSD in these sicker patients.

\section{References}

1. Blondheim DS, Jacobs LE, Kotler MN, Costacurta GA, Parry WR. Dilated cardiomyopathy with mitral regurgitation: decreased survival despite a low frequency of left ventricular thrombus. Am Heart J. 1991;122(3 Pt 1):763-71.

2. Koelling TM, Aaronson KD, Cody RJ, Bach DS, Armstrong WF. Prognostic significance of mitral regurgitation and tricuspid regurgitation in patients with left ventricular systolic dysfunction. Am Heart J. 2002;144:524-9.

3. Robbins JD, Maniar PB, Cotts W, Parker MA, Bonow RO, Gheorghiade M. Prevalence and severity of mitral regurgitation in chronic systolic heart failure. Am J Cardiol. 2003;91:360-2.

4. Trichon BH, Felker GM, Shaw LK, Cabell CH, O'Connor CM. Relation of frequency and severity of mitral regurgitation to survival among patients with left ventricular systolic dysfunction and heart failure. Am J Cardiol. 2003;91:538-43.

5. Patel JB, Borgeson DD, Barnes ME, Rihal CS, Daly RC, Redfield MM. Mitral regurgitation in patients with advanced systolic heart failure. J Card Fail. 2004;10:285-91.

6. Cleland JG, Daubert JC, Erdmann E, Freemantle N, Gras D, Kappenberger L, et al. The effect of cardiac resynchronization on morbidity and mortality in heart failure. N Engl J Med. 2005;352:1539-49.

7. O'Connor CM, Whellan DJ, Lee KL, Keteyian SJ, Cooper LS, Ellis SJ, et al. Efficacy and safety of exercise training in patients with chronic heart failure: HF-ACTION randomized controlled trial. JAMA. 2009;301:1439-50.
8. Kadish A, Dyer A, Daubert JP, Quigg R, Estes NA, Anderson KP, et al. Prophylactic defibrillator implantation in patients with nonischemic dilated cardiomyopathy. N Engl J Med. 2004;350:2151-8.

9. Bach DS, Bolling SF. Improvement following correction of secondary mitral regurgitation in end-stage cardiomyopathy with mitral annuloplasty. Am J Cardiol. 1996;78:966-9.

10. Bolling SF. Mitral reconstruction in cardiomyopathy. J Heart Valve Dis. 2002; 11(Suppl. 1):S26-31.

11. Gummert JF, Rahmel A, Bucerius J, Onnasch J, Doll N, Walther T, et al. Mitral valve repair in patients with end stage cardiomyopathy: who benefits? Eur J Cardiothorac Surg. 2003;23:1017-22; discussion 22.

12. Wu AH, Aaronson KD, Bolling SF, Pagani FD, Welch K, Koelling TM. Impact of mitral valve annuloplasty on mortality risk in patients with mitral regurgitation and left ventricular systolic dysfunction. J Am Coll Cardiol. 2005; 45:381-7.

13. Acker MA, Bolling S, Shemin R, Kirklin J, Oh JK, Mann DL, et al. Mitral valve surgery in heart failure: insights from the Acorn Clinical Trial. J Thorac Cardiovasc Surg. 2006;132:568-77. 577. e1-4.

14. Thomas JD. How leaky is that mitral valve? Simplified Doppler methods to measure regurgitant orifice area. Circulation. 1997;95:548-50.

15. Lang RM, Bierig M, Devereux RB, Flachskampf FA, Foster E, Pellikka PA, et al. American Society of Echocardiography's Nomenclature and Standards Committee; Task Force on Chamber Quantification; American College of Cardiology Echocardiography Committee; American Heart Association; European Association of Echocardiography, European Society of Cardiology. Recommendations for chamber quantification. Eur J Echocardiogr. 2006;7: 79-108.

16. Oz MC, Konertz WF, Kleber FX, Mohr FW, Gummert JF, Ostermeyer J, et al. Global surgical experience with the Acorn cardiac support device. J Thorac Cardiovasc Surg. 2003;126:983-91.

17. Braun J, Bax JJ, Versteegh MI, Voigt PG, Holman ER, Klautz RJ, et al. Preoperative left ventricular dimensions predict reverse remodeling following restrictive mitral annuloplasty in ischemic mitral regurgitation. Eur J Cardiothorac Surg. 2005;27:847-53.

18. Braun J, van de Veire NR, Klautz RJ, Versteegh MI, Holman ER, Westenberg JJ, et al. Restrictive mitral annuloplasty cures ischemic mitral regurgitation and heart failure. Ann Thorac Surg. 2008;85:430-6; discussion 6-7.

19. Dreyfus GD, Corbi PJ, Chan KM, Bahrami T. Secondary tricuspid regurgitation or dilatation: which should be the criteria for surgical repair? Ann Thorac Surg. 2005;79:127-32.

20. Starling RC, Jessup M, Oh JK, Sabbah HN, Acker MA, Mann DL, et al. Sustained benefits of the CorCap Cardiac Support Device on left ventricular remodeling: three year follow-up results from the Acorn clinical trial. Ann Thorac Surg. 2007;84:1236-42.

21. Grayburn PA, Appleton CP, DeMaria AN, Greenberg B, Lowes B, Oh J, et al. Echocardiographic predictors of morbidity and mortality in patients with advanced heart failure: the Beta-blocker Evaluation of Survival Trial (BEST). J Am Coll Cardiol. 2005;45:1064-71.

22. Ellenbogen KA, Wood MA, Klein HU. Why should we care about CARE-HF? J Am Coll Cardiol. 2005;46:2199-203.

23. Bishay ES, McCarthy PM, Cosgrove DM, Hoercher KJ, Smedira NG, Mukherjee D, et al. Mitral valve surgery in patients with severe left ventricular dysfunction. Eur J Cardiothorac Surg. 2000;17:213-21.

24. Breithardt OA, Sinha AM, Schwammenthal E, Bidaoui N, Markus KU, Franke A, et al. Acute effects of cardiac resynchronization therapy on functional mitral regurgitation in advanced systolic heart failure. J Am Coll Cardiol. 2003;41: 765-70.

25. Lancellotti P, Melon P, Sakalihasan N, Waleffe A, Dubois C, Bertholet M, et al. Effect of cardiac resynchronization therapy on functional mitral regurgitation in heart failure. Am J Cardiol. 2004;94:1462-5.

26. Sutton MG, Plappert T, Hilpisch KE, Abraham WT, Hayes DL, Chinchoy E. Sustained reverse left ventricular structural remodeling with cardiac resynchronization at one year is a function of etiology: quantitative Doppler echocardiographic evidence from the Multicenter InSync Randomized Clinical Evaluation (MIRACLE). Circulation. 2006;113:266-72.

27. Ghio S, Freemantle N, Scelsi L, Serio A, Magrini G, Pasotti M, et al. Long-term left ventricular reverse remodelling with cardiac resynchronization therapy: results from the CARE-HF trial. Eur J Heart Fail. 2009;11:480-8. 